\title{
Atypical Neurological Manifestations of Chikungunya Fever: Two Case Reports
}

\author{
Subodh Kumar Mahto, Pulin Kumar Gupta, Akanksha Singh, Ramesh Chand Meena \\ Department of Medicine, PGIMER, Dr. RML Hospital, New Delhi, India
}

\section{Abstract}

Chikungunya fever (CHIK) is an arboviral disease which is transmitted by a mosquito bite (Aedes aegypti). Fever, polyarthralgia, and maculopapular rash are hallmark clinical manifestations of this disease. These manifestations are self-liming and complete recovery is seen in most of the cases. However, atypical and lethal complications such as myocarditis, hepatitis, Guillain-Barre syndrome (GBS), and meningoencephalitis have been reported in few cases of CHIK. We hereby report two cases of chikungunya infection where rare and atypical manifestations of CHIK, i.e., GBS with bilateral lower motor facial nerve palsy, and meningoencephalitis with epidermal necrosis were seen.

Keywords: Chikungunya, Epidermal necrosis, Guillain-Barre syndrome, Meningoencephalitis

\section{INTRODUCTION}

Chikungunya fever (CHIK) is a viral disease transmitted by the bite of Aedes aegypti and Aedes albopictus. The causative agent is chikungunya virus (CHIKV), a RNA alpha virus belonging to the Togaviridae family. ${ }^{[1]}$

Outbreaks of this virus have occurred in India since 2005, and Delhi recently witnessed the outbreaks of CHIK and dengue fever in September 2016, presenting with high-grade fever, rash, arthralgia, and thrombocytopenia. ${ }^{[2]}$ However, atypical presentation and severe complications such as myocarditis, hepatitis, Guillain-Barre syndrome (GBS), and meningoencephalitis can happen rarely. ${ }^{[3]}$

\section{Case Reports}

\section{Case 1}

A 36-year-old male, a resident of Delhi, presented to our hospital with complaints of high-grade, continuous fever of 5 days' duration. He also had myalgia and multiple joint pains without signs of inflammation (arthralgia). The patient also complained of rapidly progressing weakness of all the four limbs associated with tingling sensation over the lower limb for the past 2 days and difficulty in breathing since then. On examination, the patient was conscious, oriented with stable

\begin{tabular}{|l|l|}
\hline \multicolumn{2}{|c|}{ Access this article online } \\
\hline Quick Response Code: & Website: \\
\hline & www.ijccm.org \\
\cline { 2 - 2 } & \\
\hline
\end{tabular}

vitals, and his single breath count was of 18 . Central nervous system (CNS) examination revealed all cranial nerves were normal except bilateral lower motor facial nerve palsy. There was hypotonia in bilateral lower limb, and power in bilateral lower limbs was $0 / 5$ and in upper limbs, it was $3 / 5$. Deep tendon reflexes were absent in bilateral lower limbs, while biceps and triceps reflexes in bilateral upper limbs were present (2/4). Rest of the general physical and systemic examination did not reveal any abnormality.

Blood counts were within normal limits. Tests for viral hepatitis, malaria serology, and HIV were negative. Antinuclear antibody, dengue serology, and NS1 antigen were negative, while chikungunya serology (immunoglobulin $\mathrm{M}$ [IgM] antibodies by MAC ELISA, NIV, Pune) was positive. Contrast-enhanced magnetic resonance imaging (CEMRI) brain and spine was normal, but nerve conduction study of upper and lower limbs revealed severe mixed demyelinating axonal motor sensory polyradiculoneuropathy (GBS) [Figure 1]. Lumbar puncture was done after 7 days of illness; cerebrospinal

Address for correspondence: Dr. Subodh Kumar Mahto, Department of Medicine, OPD Block, PGIMER, Dr. RML Hospital, New Delhi - 110001 , India. E-mail: drsubodhkr05@gmail.com

This is an open access journal, and articles are distributed under the terms of the Creative Commons Attribution-NonCommercial-ShareAlike 4.0 License, which allows others to remix, tweak, and build upon the work non-commercially, as long as appropriate credit is given and the new creations are licensed under the identical terms.

For reprints contact: reprints@medknow.com

How to cite this article: Mahto SK, Gupta PK, Singh A, Meena RC. Atypical neurological manifestations of chikungunya fever: Two case reports. Indian J Crit Care Med 2018;22:306-8. 
fluid (CSF) examination revealed sugar $-65 \mathrm{mg} / \mathrm{dl}$ and protein $-237 \mathrm{mg} / \mathrm{dl}$, with normal cytology suggestive of albuninocytological dissociation.

Intravenous immune globulin (IVIg), $20 \mathrm{~g} \mathrm{(400} \mathrm{mg/kg),} \mathrm{once}$ a day for 5 days along with symptomatic and supportive management was started. He had dramatic recovery and was able to stand and walk after 5 days of treatment and was discharged after 10 days of hospital stay in satisfactory condition.

\section{Case 2}

A 21-year-old female, homemaker, a resident of Bihar, admitted to our hospital with chief complaints of high-grade fever, which was intermittent in nature and associated with rashes for 1 week. She had multiple, small, reddish, nonblanchable, nonindurated, flat rashes all over the body which first appeared over the extremities followed by trunk, but palms and soles were spared. She also had myalgia and multiple joint pains without signs of inflammation (arthralgia). She developed one episode of generalized tonic-clonic seizure followed by loss of consciousness in emergency ward. On examination, the patient was unconscious with Glasgow Coma Scale score of E2V3M4. Her core temperature was $100^{\circ} \mathrm{F}$. Denuded skin lesions with dead overlying tissue

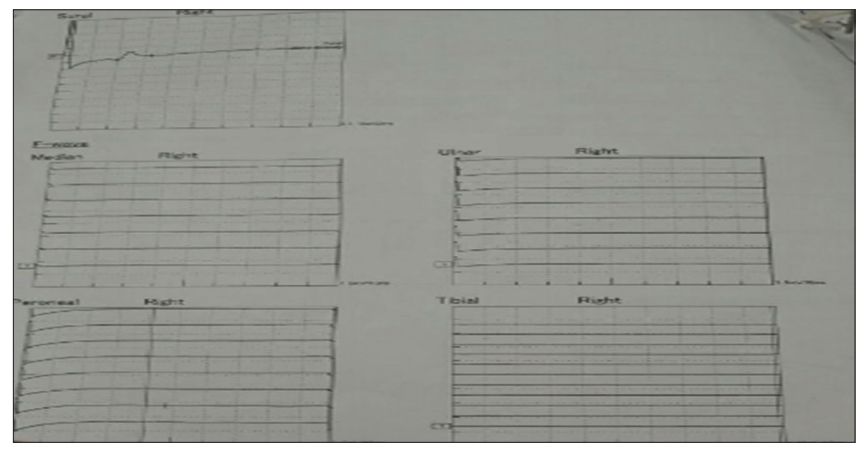

Figure 1: Nerve conduction velocity study of upper and lower limbs releaved severe mixed demyelinating axonal motor sensory polyradiculoneuropathy

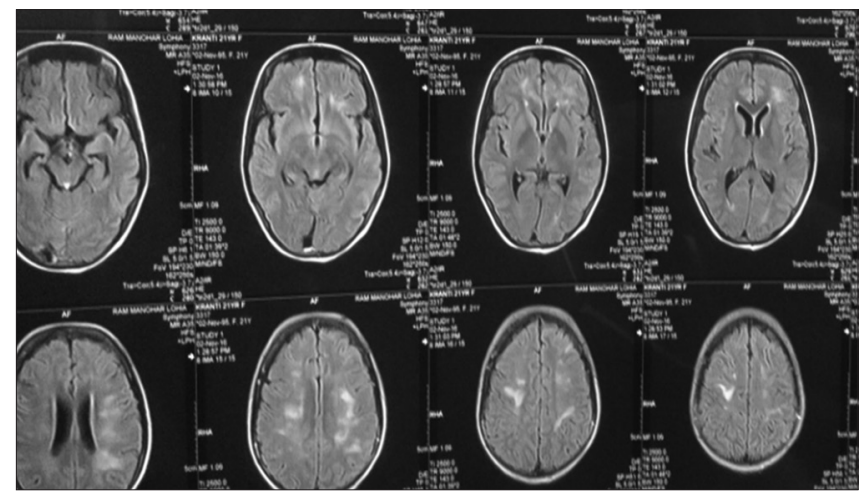

Figure 3: Contrast-enhanced magnetic resonance imaging of brain (T1-weighted) showed multiple discrete subcortical and deep white matter patches of altered signal intensity in bilateral frontoparietal and occipital lobes were present over both forearms, shoulders, chest and back, hips, anterior part of thigh, and both elbows, approximately $2 \mathrm{~cm} \times 4 \mathrm{~cm}$ in size, there were irregular margins with active discharge [Figure 2]. CNS examination revealed diminished DTR with extensor bilateral planters, and rest of the examination was within normal limits. Chikungunya serology (IgM antibody by MAC ELISA, NIV, Pune) was positive, while rest of the laboratory parameters were within normal limits. CSF examination revealed sugar $-74 \mathrm{mg} / \mathrm{dl}$, protein $-102 \mathrm{mg} / \mathrm{dl}$, and total leukocyte count $-2-5$ cells with predominantly lymphocytes. CEMRI of the brain showed multiple discrete subcortical and deep white matter patches of altered signal intensity in bilateral, frontoparietal, and occipital lobes [Figure 3], while T2/fluid-attenuated inversion recovery brain showed multiple patches of hyperintensities in both frontal and parietal lobes, with white matter suggestive of encephalitis [Figure 4].

The patient was managed conservatively with injection ceftriaxone intravenous (i.v.) twice a day and steroids. The patient regained consciousness on the $3^{\text {rd }}$ day and was discharged after 14 days of hospital stay with stable vitals.

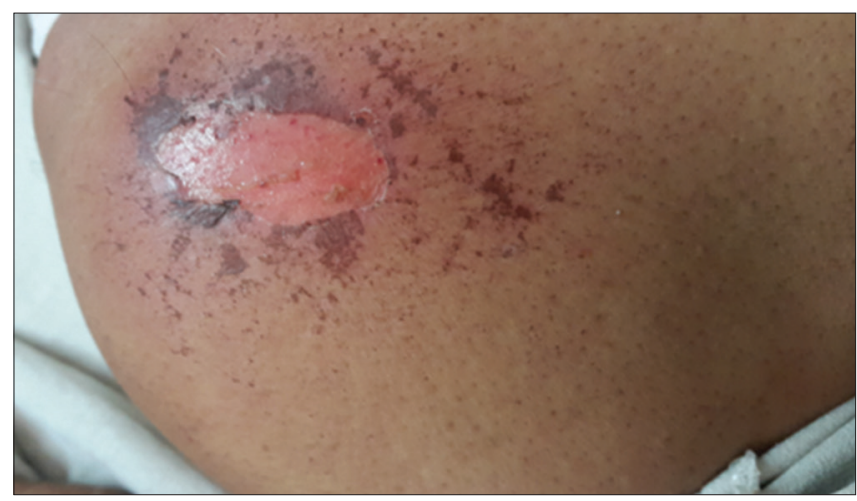

Figure 2: Skin lesion



Figure 4: Contrast-enhanced magnetic resonance imaging brain (T2/fluid-attenuated inversion recovery) showed multiple patches of hyperintensities in both frontal and parietal lobes, with white matter suggestive of encephalitis 


\section{Discussion}

Various neurological complications associated with CHIKV have been described such as meningoencephalitis, myelitis, GBS, encephalitis, myelopathy, peripheral neuropathy, myeloneuropathy, and myopathy. ${ }^{[3]}$ Due to the various neurological manifestations, CHIKV is strongly suspected to have neurotropic, but it has not been well studied like other neurotropic arboviruses including alphaviruses species, such as Eastern equine encephalitis and Venezuelan equine encephalitis. ${ }^{[4]}$ Here, we have reported two cases of CHIKV with not so common neurological manifestation, i.e., meningoencephaitis and GBS, respectively. In a case series by Chandak et al.$^{[3]}$ from Nagpur, various neurological complications of CHIKV infection were reported. However, in their case series, the neuropathy was predominantly demyelinating type. Whereas in our case, the neuropathy was a mixed type.

In the second case, our patient presented with chikungunya encephalitis with scalded skin syndrome. Erythematous or maculopapular rashes, which are found in $25 \%-39 \%$ of patients with neuro-chikungunya, ${ }^{[5]}$ might be more helpful in differentiating because they are not features of Japanese encephalitis or herpes simplex encephalitis. ${ }^{[6]}$ Scalded skin syndrome seen in our patient is very rarely reported with CHIKV.

\section{Conclusion}

Although CHIK is a self-limiting disease, systemic and organ-specific manifestation of chikungunya infection can be seen in various ways like in our case and CHIKV should be kept in mind while managing these medical emergencies.

\section{Declaration of patient consent}

The authors certify that they have obtained all appropriate patient consent forms. In the form the patient(s) has/have given his/her/their consent for his/her/their images and other clinical information to be reported in the journal. The patients understand that their names and initials will not be published and due efforts will be made to conceal their identity, but anonymity cannot be guaranteed.

\section{Financial support and sponsorship}

Nil.

\section{Conflicts of interest}

There are no conflicts of interest.

\section{References}

1. Lemant J, Boisson V, Winer A, Thibault L, André H, Tixier F, et al. Serious acute chikungunya virus infection requiring intensive care during the reunion Island outbreak in 2005-2006. Crit Care Med 2008;36:2536-41.

2. Lahariya C, Pradhan SK. Emergence of chikungunya virus in Indian subcontinent after 32 years: A review. J Vector Borne Dis 2006;43:151-60.

3. Chandak NH, Kashyap RS, Kabra D, Karandikar P, Saha SS, Morey SH, et al. Neurological complications of chikungunya virus infection. Neurol India 2009;57:177-80.

4. O'Leary DR, Kuhn S, Kniss KL, Hinckley AF, Rasmussen SA, Pape WJ, et al. Birth outcomes following west Nile virus infection of pregnant women in the United States: 2003-2004. Pediatrics 2006;117:e537-45.

5. Wadia RS. A neurotropic virus (chikungunya) and a neuropathic amino acid (homocysteine). Ann Indian Acad Neurol 2007;10:198-13.

6. Lebrun G, Chadda K, Reboux AH, Martinet O, Gaüzère BA. Guillain-Barré syndrome after chikungunya infection. Emerg Infect Dis 2009;15:495-6. 